\title{
Fallacy of wide undrained strength range at the Casagrande liquid limit
}

Brendan C. O'Kelly PhD, CEng, CEnv, MICE, FTCD

Associate Professor, Department of Civil, Structural and Environmental

Engineering, Trinity College Dublin, Dublin, Ireland (bokelly@tcd.ie)

(Orcid:0000-0002-1343-4428)

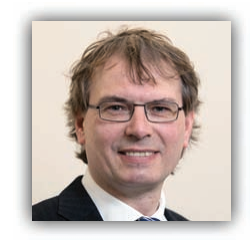

The liquid limit (LL), as originally proposed by Atterberg, is notionally the water content below which fine-grained soil ceases to flow as a liquid. In many countries, the Casagrande-cup approach is the standard procedure for LL determinations. For remoulded fine-grained soil, the undrained shear strength $\left(s_{\mathrm{u}}(\mathrm{LL})\right)$ corresponding to the Casagrande LL water content $\left(w_{\mathrm{L}(\text { cup })}\right)$ value can range $\mathbf{0 . 7 - 3 . 9} \mathrm{kPa}$, but typically $\mathbf{1 . 0}-\mathbf{2} .7 \mathrm{kPa}$, with many researchers agreeing on a

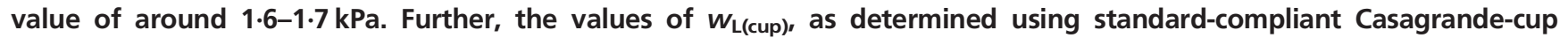
devices, correspond to a specific strength value of $-1.0 \mathrm{~m}^{2} / \mathrm{s}^{2}$, such that the value of $s_{u(L L)}$ reduces with increasing $w_{\mathrm{L} \text { (cup). }}$ A few research papers have, however, reported significantly higher $s_{\mathrm{u}(\mathrm{LL})}$ values ( $>4 \mathrm{kPa}$ and up to $12 \mathrm{kPa}$ ) for some fine-grained soils investigated. This paper critiques these experimental data and debunks this myth by first considering how these superhigh $s_{\mathrm{u}(\mathrm{LL})}$ values were deduced and then explaining why they are not correct. For low- to very high-plasticity soils, the overwhelming weight of experimental evidence presented indicates that $s_{\mathrm{u}(\mathrm{LL})}$ can range $1-3 \mathrm{kPa}$ and typically decreases from approximately 2.5 to $1.6 \mathrm{kPa}$ for $w_{\mathrm{L}(\text { cup) }}$ increasing from 20 to $70 \%$.

\section{Notation}

$a, b \quad$ empirical parameters defining the exponential $I_{\mathrm{L}}-S_{\mathrm{u}}$ relationship

$I_{\mathrm{L}} \quad$ liquidity index

$I_{\mathrm{P}} \quad$ plasticity index

$n \quad$ number of data entries

$R^{2} \quad$ coefficient of determination

$R_{\mathrm{S}} \quad$ factor gain in remoulded undrained shear strength considering the full plastic range

$S_{\mathrm{s}} \quad$ specific strength

$s_{\mathrm{u}} \quad$ remoulded undrained shear strength

$s_{\mathrm{u}(\mathrm{LL})} \quad$ remoulded undrained shear strength at the liquid limit water content

$s_{\mathrm{u}(\mathrm{PL})} \quad$ remoulded undrained shear strength at the plastic limit water content

$w \quad$ water content

$w_{\text {L(cup) }}$ water content at the Casagrande-cup liquid limit

$w_{\mathrm{P}} \quad$ plastic limit

$\sigma \quad$ standard deviation

\section{Introduction}

The liquid limit (LL), originating from the original research of Atterberg (1911a, 1911b) and introduced into soil mechanics by Terzaghi (1926a, 1926b), with the associated percussion-cup test method standardised by Casagrande $(1932,1958)$, is notionally the water content below which fine-grained soil ceases to flow as a liquid. LL testing is widely specified in geotechnical engineering practice, with the percussion-cup approach being the standardised LL test methodology employed in much of the world. In essence, a brass cup containing remoulded fine-grained soil paste through which a standardised groove has been cut is repeatedly dropped through a fixed distance of $10 \mathrm{~mm}$ onto a rubber base, with the Casagrande LL (i.e. $w_{\mathrm{L}(\text { cup) }}$ ) defined as the water content value for which 25 blows are required for the plastic flow of the soil paste to close the groove.

The LL parameter is a part of the consistency limits, with the experimental $w_{\mathrm{L}(\mathrm{cup})}$, thread-rolling plastic limit (PL) $\left(w_{\mathrm{P}}\right)$ and plasticity index $\left(I_{\mathrm{P}}\right)$ being correlated with various soil properties, such as shear strength (e.g. see reviews in the papers by Das et al. (2013), Nagaraj et al. (2012), O'Kelly (2013a) and O'Kelly et al. (2018)), as well as for soil classification purposes using the standard plasticity chart. While the thread-rolling PL test determines a genuine observable transition in soil behaviour from a plastic to semi-solid state, as discussed by Haigh et al. (2013), the LL is essentially arbitrary in nature - that is, no distinct change in soil behaviour is observable at this 'transition' water content. As such, it has been widely recognised that the value of water content assigned to the Casagrande LL for a given finegrained soil is dependent on the precise characteristics of the test method and the class of Casagrande-cup device employed in its determination (Casagrande, 1958; Haigh, 2016; Norman, 1958; 
Sridharan and Prakash, 2000; Whyte, 1982). The most significant variations in the Casagrande-cup devices specified in national codes are differences in the devices' base hardness and resilience values (Haigh, 2016; Whyte, 1982). Casagrande-cup devices are generally categorised as having hard or softer base materials, as, for example, are the ASTM and BSI Casagrande-cup devices, respectively, although the precise nature of a device within each of these categories is not rigidly defined according to Haigh (2016). In terms of mobilised undrained shear strength, softerbase devices produce higher $w_{\mathrm{L}(\mathrm{cup})}$ values and hence lower values of remoulded undrained shear strength at the LL water content (i.e. $s_{\mathrm{u}(\mathrm{LL})}$ ) compared with hard-base devices (Dragoni et al., 2008; Haigh, 2016; Norman, 1958; Sridharan and Prakash, 2000; Whyte, 1982).

The associated value of remoulded undrained shear strength for the LL depends on the following, which are elaborated in subsequent paragraphs

- approach and methodology of remoulded undrained shear strength $\left(s_{\mathrm{u}}\right)$ measurement and its variation with water content $(w)$

method of interpolation or extrapolation of the obtained $s_{\mathrm{u}}-w$ data set for the determination of the $s_{\mathrm{u}(\mathrm{LL})}$ value associated with the measured $w_{\mathrm{L}(\text { cup })}$ value.

In previous investigations on this topic, reported strength measurements were invariably obtained using miniature vane-shear devices, investigating a range of different water content values close to the LL (Youssef et al., 1965) or a range of wider water contents within the plastic range (Kayabali and Tufenkci, 2010; Wasti and Bezirci, 1986). As with any strength-measurement approach, the mobilised shear strength value depends on many factors, including the test specimens' confinement stress, boundary and drainage conditions and also the shearing mode and shear strain rate (O'Kelly, 2014a). For instance, faster shearing rates would produce higher $s_{\mathrm{u}}$ values (Ladd and Foott, 1974). For vane shear, specimen drainage could occur for higher-permeability finegrained soils (e.g. those with high fine sand and/or silt contents) that are sheared too slowly, such that their mobilised strengths (partially drained) would be greater than their truly undrained strength values for the particular water contents under investigation.

The Casagrande $s_{\mathrm{u}(\mathrm{LL})}$ value is generally deduced from regression analysis, adopting either semi-logarithmic (Kayabali and Tufenkci, 2010; Skempton and Northey, 1952; Wasti and Bezirci, 1986) or the preferred bi-logarithmic (O'Kelly, 2014a, 2014b; O'Kelly and Sivakumar, 2014; Sharma and Bora, 2003; Youssef et al., 1965) presentations of the measured $s_{\mathrm{u}}-w$ data. The data sets can comprise $s_{\mathrm{u}}$ values for narrow ranges of water content $<\mathrm{LL}$ or may also include some $s_{\mathrm{u}}$ values measured for water contents $>\mathrm{LL}$ or may consider a wide range of water content values covering the plastic range. The number of $s_{\mathrm{u}}-w$ data pairs for each soil analysis can vary (generally a minimum of four or five are presented (Kayabali and Tufenkci, 2010; Vinod et al., 2013a)). Considerable scatter may be evident in the produced $s_{\mathrm{u}}-w$ data plot, and the reproducibility of the $s_{\mathrm{u}}$ values for a given value of water content is invariably not reported. All of the aforementioned factors have a bearing on the interpolated value of $s_{\mathrm{u}(\mathrm{LL})}$ for a given soil under investigation. Ideally, the data set for a given soil would comprise $s_{\mathrm{u}}$ measurements for a minimum of five to seven water content values about the LL, including a couple of $s_{\mathrm{u}}$ measurements for water contents $>$ LL. The format in which the $s_{\mathrm{u}}-w$ data are plotted and subsequently analysed influences the interpolated value of $s_{\mathrm{u}(\mathrm{LL})}$, with the bi-logarithmic plot presentation often preferred over the semi-logarithmic approach when considering a wide range of water content values (Butterfield 1979; O'Kelly 2014a) - for example, for $s_{\mathrm{u}}-w$ data obtained over the plastic range for very high-plasticity soil. However, when analysing a narrow range of water contents about the LL, the $s_{\mathrm{u}}$ against $w$ plot, with the former presented on a logarithmic scale, may be more appropriate. Note that there is experimental evidence suggesting that, for some bentonite soils investigated ( $w_{\mathrm{L}(\mathrm{cup})}=$ $210-460 \%$ ), the linear characteristic of the bi-logarithmic $s_{\mathrm{u}}-w$ data plot may not apply when considering data covering the full plastic range (see Figure 1), but rather the relationship is bi-linear (Sharma and Bora, 2003), such that caution is required in the determination of their $s_{\mathrm{u}(\mathrm{LL})}$ values from analysis of $s_{\mathrm{u}}-w$ data.

For each of the earlier bullet points, there are possibilities for significant experimental errors arising, for instance, from the use of non-compliant Casagrande-cup devices (Haigh, 2016) or due to operator deficiencies in performing the tests and/or associated with interpretation of the experimental data. Clearly, interpolation or extrapolation of $s_{\mathrm{u}}-w$ data plots containing some scatter could result in either under- or over-prediction of the actual $s_{\mathrm{u}}$ value corresponding to the $w_{\mathrm{L}(\text { cup) }}$ value. Further, since the LL is defined for the remoulded condition, it follows that the measured $s_{\mathrm{u}}$ values are for freshly remoulded specimens - that is, cured or

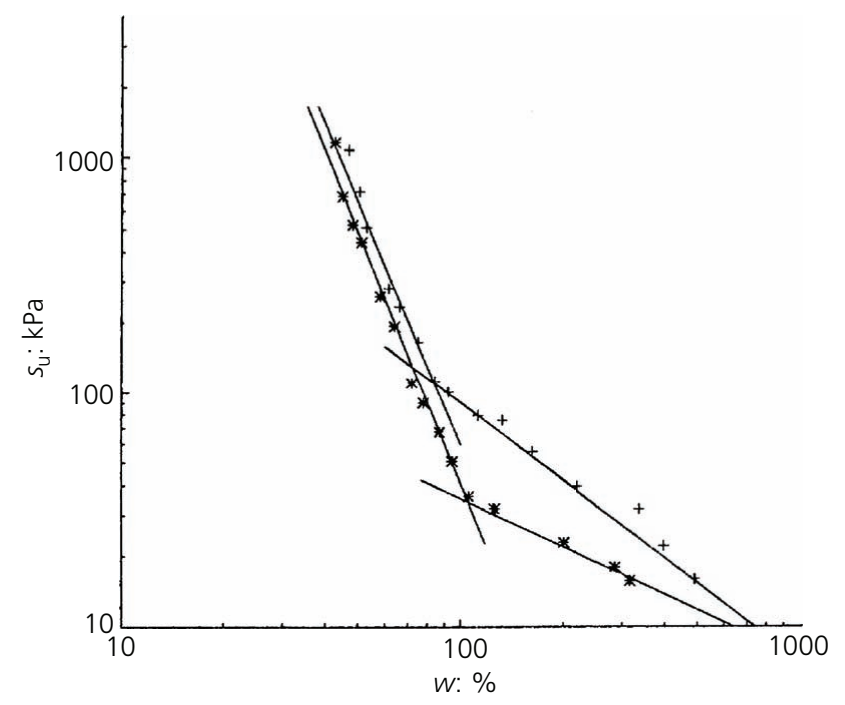

Figure 1. Bi-logarithmic $s_{u}-W$ data plots for two pure bentonite soils (adopted from Sharma and Bora (2003) with permission from ASCE) 
undisturbed test specimens would mobilise higher $s_{\mathrm{u}}$ values compared to remoulded specimens. As per standard practice, LL tests are performed on the soil fraction passing a $425 \mu \mathrm{m}$ sieve (ASTM, 2017a; BSI, 1990), but the shear strength tests may be performed for a wider or the entire soil grading, in which case the soil fabric arising from coarser particles present may also result in higher $s_{\mathrm{u}}$ values compared to that mobilised for the fraction passing the $425 \mu \mathrm{m}$ sieve.

Based on previous experimental investigations presented in the literature (Table 1), the value of miniature vane $s_{\mathrm{u}(\mathrm{LL})}$ for remoulded inorganic fine-grained soil at the Casagrande LL can range $0.7-3.9 \mathrm{kPa}$, but typically $1 \cdot 0-2.7 \mathrm{kPa}$, with many researchers agreeing on an average $s_{\mathrm{u}(\mathrm{LL})}$ value of around 1.6-1.7 kPa (Sharma and Bora, 2003; Whyte, 1982; Wroth and Wood, 1978; Youssef et al., 1965). Other experimental approaches, including moisture-tension testing by Russel and Mickel (1970), have suggested that the values of $s_{\mathrm{u}(\mathrm{LL})}$ for finegrained soils are within a narrower range of about $1 \cdot 7-2 \cdot 0 \mathrm{kPa}$.
Furthermore, it is well brought out in the literature that the value of $s_{\mathrm{u}(\mathrm{LL})}$ decreases with increasing $w_{\mathrm{L}(\mathrm{cup})}$, as demonstrated on a bilogarithmic $s_{\mathrm{u}(\mathrm{LL})}$ against $w_{\mathrm{L}(\mathrm{cup})}$ data plot for 26 very different finegrained soils covering the LL range $32-190 \%$ investigated in the paper by Youssef et al. (1965). The trend is also strongly evident when the tabulated pairs of $w_{\mathrm{L}(\text { cup })}$ and $s_{\mathrm{u}(\mathrm{LL})}$ values reported for 16 different fine-grained soils ( $w_{\mathrm{L} \text { (cup) }}=32 \cdot 6-324 \%$ ) in the paper by Das et al. (2013) are presented in a bi-logarithmic $s_{\mathrm{u}(\mathrm{LL})}$ against $w_{\mathrm{L}(\mathrm{cup})}$ chart. This characteristic behaviour occurs since the $w_{\mathrm{L} \text { (cup) }}$ corresponds to specific strength $\left(S_{\mathrm{s}}\right.$, i.e. the ratio of $s_{\mathrm{u}}$ to soil density) values of $\sim 1.07$ and $0.94 \mathrm{~m}^{2} / \mathrm{s}^{2}$ for the ASTM and BSI cup devices, respectively (Haigh, 2012), such that the value of $s_{\mathrm{u}(\mathrm{LL})}$ must be lower for higher-LL soils since they invariably have lower particle density and hence lower soil density values.

However, for a handful of research papers on this topic, superhigh values of Casagrande $s_{\mathrm{u}(\mathrm{LL})}$ have been reported (Table 2). These include the often-quoted investigations by Wasti and Bezirci (1986) and Kayabali and Tufenkci (2010), which report deduced

Table 1. Narrow variation in vane $S_{u(L L)}$ reported for inorganic fine-grained soils

\begin{tabular}{|c|c|c|c|c|}
\hline$S_{\mathrm{u}(\mathrm{LL}): \mathrm{kPa}}$ & $W_{\mathrm{L}(\text { cup }):} \%$ & $\begin{array}{l}\text { Number of } \\
\text { samples, } n\end{array}$ & Remark & Reference \\
\hline $0 \cdot 7-1 \cdot 75$ & 30-97 & 4 & BSI cup. Interpolated from reported $I_{L}-S_{U}$ data & $\begin{array}{l}\text { Skempton and } \\
\text { Northey (1952) }\end{array}$ \\
\hline $2-3$ & & - & ASTM cup. Suggested mean $S_{u(L L)}=2.65 \mathrm{kPa}$ & Casagrande (1958) \\
\hline $0 \cdot 8-1 \cdot 6$ & $41-72$ & 5 & BSI cup & Norman (1958) \\
\hline $1 \cdot 1-2 \cdot 3$ & $41-72$ & 5 & ASTM cup: $S_{u(L L)}$ values $25-50 \%$ greater compared to those by BSI cup & Norman (1958) \\
\hline $2 \cdot 5$ & & & ASTM cup & Seed et al. (1964) \\
\hline $1 \cdot 3-2 \cdot 4$ & $32-190$ & 26 & $\begin{array}{l}\text { ASTM cup. Inverse bi-logarithmic } S_{\mathrm{u}(\mathrm{LL})}-W_{\mathrm{L}(\mathrm{cup})} \text { correlation. } \\
\text { Mean } S_{\mathrm{u}(\mathrm{LL})}=1.7 \mathrm{kPa}\end{array}$ & Youssef et al. (1965) \\
\hline $1-3$ & $17-382$ & & Softer-base cup device & $\begin{array}{l}\text { Škopek and Ter- } \\
\text { Stepanian (1975) }\end{array}$ \\
\hline $0.7-2 \cdot 65$ & & - & $\begin{array}{l}\text { From synthesis of various published data sets, } 1.7 \mathrm{kPa} \text { adopted as best } \\
\text { estimate for } S_{\mathrm{u}(\mathrm{LL})}\end{array}$ & $\begin{array}{l}\text { Wroth and Wood } \\
\text { (1978) }\end{array}$ \\
\hline $1 \cdot 6$ & & - & Deduced mean $S_{u(L L)}$ value for BSI cup & Whyte (1982) \\
\hline $1 \cdot 7$ & & - & Deduced mean $s_{u(L L)}$ value for ASTM cup & Whyte (1982) \\
\hline $0 \cdot 66-1 \cdot 35$ & $29 \cdot 8-100 \cdot 8$ & & Viscometer used for strength determinations & $\begin{array}{l}\text { Sridharan and } \\
\text { Prakash (1998) }\end{array}$ \\
\hline$\sim 2$ & & & ASTM cup & $\begin{array}{l}\text { ASTM D } 4318-00 \\
\text { (ASTM, 2000) }\end{array}$ \\
\hline$\sim 1 \cdot 7-2 \cdot 0$ & & - & $\begin{array}{l}\text { Attributed to same average adsorbed water-layer thickness on all particle } \\
\text { surfaces at LL }\end{array}$ & Mitchell (2005) \\
\hline $1 \cdot 2-2 \cdot 6$ & $32 \cdot 6-324$ & 16 & $\begin{array}{l}\text { Softer-base cup (ISI, 1985). One stray data point with } S_{u(L L)}=16 \mathrm{kPa} \text {. } \\
\text { Excluding the stray point gives mean } S_{\mathrm{u}(\mathrm{LL})}=1.7 \mathrm{kPa}\end{array}$ & Das et al. (2013) \\
\hline $0.9-3.9$ & & & General trend of $S_{\mathrm{u}(\mathrm{LL})}$ reducing in value with increasing water content & Haigh (2016) \\
\hline
\end{tabular}

Table 2. Reported superwide $S_{\mathrm{u}(L \mathrm{~L})}$ ranges under scrutiny in the present investigation

\begin{tabular}{|c|c|c|c|c|}
\hline$s_{\mathrm{u}(\mathrm{LL})}: \mathrm{kPa}$ & $w_{\mathrm{L}(\text { cup })}: \%$ & $\begin{array}{l}\text { Number of } \\
\text { samples, } n\end{array}$ & Remark & Reference \\
\hline $0 \cdot 5-5 \cdot 6$ & $27-526$ & 24 & $\begin{array}{l}\text { Hard-base cup device. For } W_{\mathrm{L}(\text { cup })}=27-110 \% \text {, mean } S_{\mathrm{u}(\mathrm{LL})}= \\
2 \cdot 7 \mathrm{kPa}(n=15) \\
\text { Considering all } 24 \text { soils investigated, mean } S_{\mathrm{U}(\mathrm{LL})}=2 \cdot 15 \mathrm{kPa}\end{array}$ & Wasti and Bezirci (1986) \\
\hline $1 \cdot 2-12 \cdot 0$ & $26 \cdot 4-83 \cdot 6$ & 15 & & $\begin{array}{l}\text { Kayabali and Tufenkci } \\
(2010)\end{array}$ \\
\hline $5 \cdot 3-7 \cdot 0$ & $37-234$ & 9 & Interpolated mean $S_{u(L L)}=5.8 \mathrm{kPa}$ & Vinod et al. (2013a) \\
\hline
\end{tabular}


values of miniature vane $s_{\mathrm{u}(\mathrm{LL})}$ ranging $0.5-5.6 \mathrm{kPa}$ (with an average value of $2 \cdot 15 \mathrm{kPa}$ ) and $1 \cdot 2-12 \cdot 0 \mathrm{kPa}$, respectively, for $w_{\mathrm{L}(\mathrm{cup})}$ values determined using hard-base Casagrande-cup devices. In other words, the experimental data presented by these researchers are suggesting a possible one-order-of-magnitude variation in the remoulded undrained shear strength for the LL condition. A third and more recently published investigation, that of Vinod et al. (2103a), reports excessively high deduced values of miniature vane $s_{\mathrm{u}(\mathrm{LL})}$ ranging $5 \cdot 3-7 \cdot 0 \mathrm{kPa}$, with an interpolated mean value of $5 \cdot 8 \mathrm{kPa}$, for nine very different fine-grained soils investigated. The deduced upper-bound $s_{\mathrm{u}(\mathrm{LL})}$ values of $5 \cdot 6,12 \cdot 0$ and $7 \cdot 0 \mathrm{kPa}$ reported in these three investigations grossly exceed the general consensus upper-bound $s_{\mathrm{u}(\mathrm{LL})}$ value of $\sim 3.9 \mathrm{kPa}$ associated with the Casagrande-cup approach. Nonetheless, these excessively high $s_{\mathrm{u}(\mathrm{LL})}$ values have been used in some recent research papers to support various hypotheses. These include, for example, that the Casagrande $s_{\mathrm{u}(\mathrm{LL})}$ value can vary over a wide range (Nagaraj et al., 2012, 2018), such that the value of $w_{\mathrm{L} \text { (cup) }}$ determined for a given soil using the Casagrande-cup device can have wide variability and hence may be seen as less reliable when compared to the alternative fall-cone LL approach. For instance, Nagaraj et al. (2012) observed that the variation in undrained shear strength at the LL is nearly 60 times - that is, from $s_{\mathrm{u}(\mathrm{LL})}$ values of as low as $0.2 \mathrm{kPa}$ to as high as $12 \mathrm{kPa}$. It is, however, simply not possible for remoulded fine-grained soil to have such high undrained shear strength values at the transition from the viscous liquid (slurry) state to the plastic state.

The purpose of this paper, therefore, is to present independent analyses of the Kayabali and Tufenkci (2010) and Wasti and Bezirci (1986) $s_{\mathrm{u}}-w$ data sets, to postulate rational explanations as to how the aforementioned superhigh $s_{\mathrm{u}(\mathrm{LL})}$ values were deduced and, furthermore, to explain why they are not correct. This is an important and significant point since, as already mentioned, one major use of the LL parameter, as a part of the consistency limits, is in various empirical correlations with other soil properties, including undrained shear strength. For example, overestimated values of undrained shear strength based on unconservative $s_{\mathrm{u}(\mathrm{LL})}$ values may cause dangerous situations.

As a starting point, the author assumed that the experimental $s_{\mathrm{u}}-w$ data sets given for the various fine-grained soils investigated in the papers by Kayabali and Tufenkci (2010), Wasti and Bezirci (1986) and Vinod et al. (2013a) were correct, but the reported analyses and presented assessments for some of these data were not optimum, thereby resulting in some superhigh deduced $s_{\mathrm{u}(\mathrm{LL})}$ values. In other words, the $s_{\mathrm{u}(\mathrm{LL})}$ values reported in these three investigations are deduced values, not measured values, and as such are open to reinterpretation. Since superhigh $s_{\mathrm{u}(\mathrm{LL})}$ values may be deduced for a whole variety of reasons, the approach adopted in the present investigation was to present separate critiques for the pertinent parts of each of these papers followed by an overarching discussion section. Compared with the values presented by Wasti and Bezirci (1986), the deduced upper-bound values and range of $s_{\mathrm{u}(\mathrm{LL})}$ are significantly greater in the case of

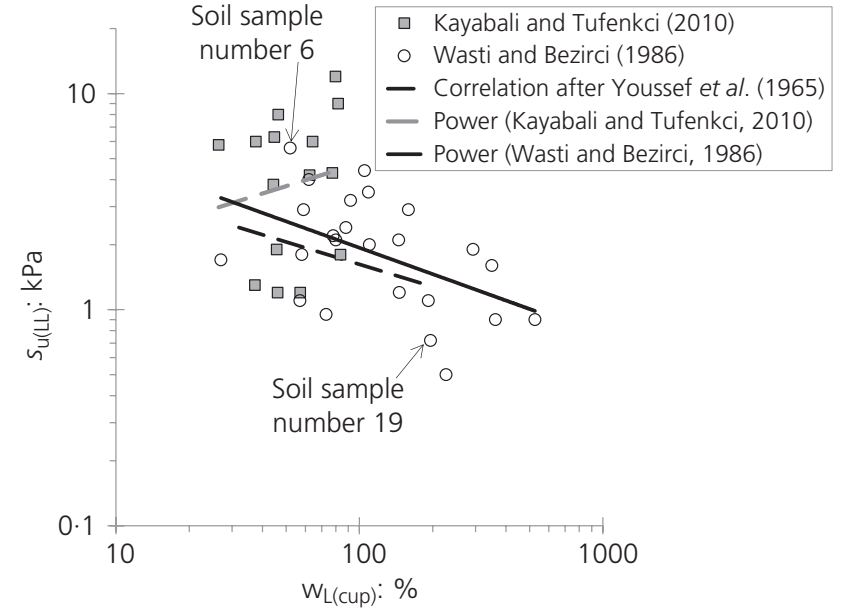

Figure 2. Variation in $S_{\mathrm{u}(\mathrm{LL})}$ with $W_{\mathrm{L}(\mathrm{cup})}$ for various fine-grained soils presented in bi-logarithmic chart (data after Kayabali and Tufenkci (2010) and Wasti and Bezirci (1986))

the Kayabali and Tufenkci (2010) data set (see Figure 2), such that the latter investigation is considered first in this reassessment.

\section{Kayabali and Tufenkci (2010)}

In their paper, Kayabali and Tufenkci (2010) reported mean and standard deviation $(\sigma)$ values of $w_{\mathrm{L}(\mathrm{cup})}$ determined for 15 inorganic fine-grained soils in accordance with ASTM D 4318-00 (ASTM, 2000). The mean and $\sigma$ values were determined from statistical analysis of data obtained from 15 Casagrande-cup LL and 15 thread-rolling PL tests repeated for each soil by different operators in the same laboratory. On the basis of its mean value of $w_{\mathrm{L}(\text { cup })}$ and deduced $I_{\mathrm{P}}$, each soil was classified according to its plot position in the standard plasticity chart (Figure 3), with the

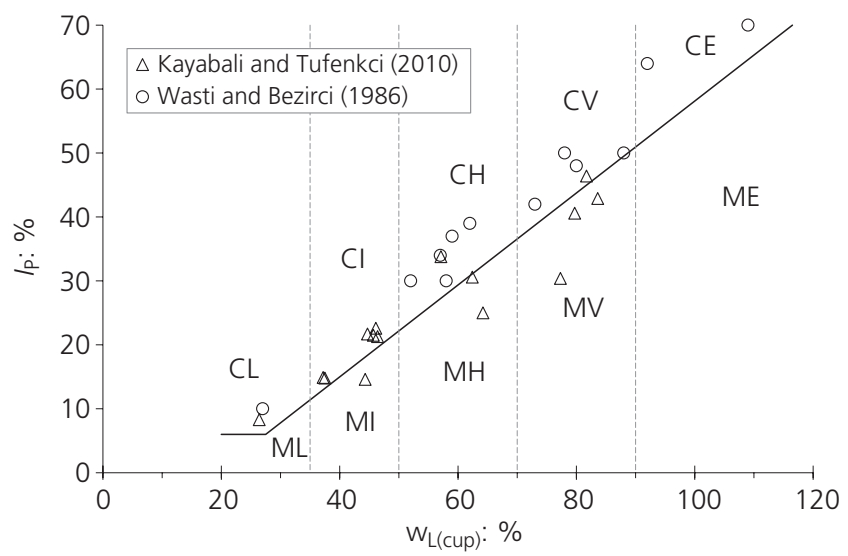

Figure 3. Standard plasticity chart (BS 5930 (BSI, 2015)). Note that ten of the clay soils comprising the Wasti and Bezirci (1986) data set do not appear in this plot since their values of $W_{\mathrm{L} \text { (cup) }}$ $>120 \%$ (ranging 145-526\%). CE, clay extremely high-plasticity; $\mathrm{CH}$, clay high; $\mathrm{Cl}$, clay intermediate; $\mathrm{CL}$, clay low; $\mathrm{CV}$, clay very high; ME, silt extremely high-plasticity; $\mathrm{MH}$, silt high; $\mathrm{MI}$, silt intermediate; ML, silt low; MV, silt very high 
soils ranging from low to very high plasticity (mean $w_{\mathrm{L}(\text { cup })}=$ $26 \cdot 4-83 \cdot 6 \%$ ). In addition, miniature vane $s_{\mathrm{u}}$ measurements for five to seven different water content values within the identified plastic ranges were reported for each soil. Then, the values of $s_{\mathrm{u}(\mathrm{LL})}$ corresponding to their mean $w_{\mathrm{L}(\text { cup })}$ values were deduced from extrapolation of their semi-logarithmic $s_{\mathrm{u}}-w$ data plots. No information is provided in the Kayabali and Tufenkci (2010) paper on the details of performing the shear-vane tests or on their repeatability. Based on the deduced $s_{\mathrm{u}(\mathrm{LL})}$ values and after excluding their extreme values, Kayabali and Tufenkci (2010) concluded that for these low- to very high-plasticity fine-grained soils, a rough average of the deduced $s_{\mathrm{u}(\mathrm{LL})}$ is about $5 \mathrm{kPa}$.

As part of the present investigation, using the tabulated $s_{\mathrm{u}}-w$ data pairs presented for the 15 fine-grained soils in their paper, the author performed an independent analysis to establish the values of $s_{\mathrm{u}(\mathrm{LL})}$ corresponding to the reported mean $w_{\mathrm{L}(\mathrm{cup})}$ values. This analysis employed the semi-logarithmic plot approach employed by Kayabali and Tufenkci (2010) and also the bi-logarithmic plot presentation of the data, suggested as superior by some researchers, for regression and extrapolation of the original data sets. The results of the author's analysis are presented in Table 3, with the coefficient of determination $\left(R^{2}\right)$ values of the best-fit lines ranging $0 \cdot 8799-0.9934$ and $0 \cdot 8724-0.9950$ for the semiand bi-logarithmic plots, respectively. Although there are some variations (up to $1.5 \mathrm{kPa}$ ), the computed $s_{\mathrm{u}(\mathrm{LL})}$ values determined using the semi-logarithmic regression and extrapolation approach are in general agreement with those reported by Kayabali and Tufenkci (2010), substantially confirming their data analysis. Compared to the semi-logarithmic approach, the bi-logarithmic regression and extrapolation approach was found to produce marginally higher $s_{\mathrm{u}(\mathrm{LL})}$ values consistently. These analyses were repeated for each soil to establish the $s_{\mathrm{u}}$ value corresponding to its $95 \%$ confidence interval value of $w_{\mathrm{L}(\mathrm{cup})}-$ that is, the mean $w_{\mathrm{L}(\text { cup })} \times(1+2 \sigma)$, with these results also presented in Table 3 . From the data reported in their paper; it is noted that the measured $w_{\mathrm{L} \text { (cup) }}$ values for the six silt materials had much larger variation than those for the nine clay materials which together comprised the group of 15 soils investigated, with $\sigma$ values in the ranges $2 \cdot 4-9 \cdot 5$ and $0 \cdot 6-4 \cdot 6$ percentage points, respectively.

Referring to Table 3; for reported mean $w_{\mathrm{L}(\mathrm{cup})}$ values and based on the semi-logarithmic plot approach, values of $s_{\mathrm{u}(\mathrm{LL})}$ ranging $3 \cdot 5-13 \cdot 3 \mathrm{kPa}$ were deduced for five of the six silt materials and $4 \cdot 9-8 \cdot 9 \mathrm{kPa}$ for five of the nine clay materials investigated by Kayabali and Tufenkci (2010). Further, the mean of the $s_{\mathrm{u}(\mathrm{LL})}$ values deduced for the six silt materials of $5.7 \mathrm{kPa}$ was greater than that for the nine clay materials $(4 \cdot 6 \mathrm{kPa})$. The minimum value of $s_{\mathrm{u}(\mathrm{LL})}$ deduced from all these analyses was $1.1 \mathrm{kPa}$ for the clay soil B-05. For credible upper-bound LL water contents (i.e. mean $\left.w_{\mathrm{L}(\text { cup })} \times(1+2 \sigma)\right)$, again based on the semilogarithmic plot approach, two of the six silt materials and three of the nine clay materials were found to have deduced $s_{\mathrm{u}(\mathrm{LL})}$ values in the range $2 \cdot 5-5 \cdot 8 \mathrm{kPa}$. On both counts, these ranges of $s_{\mathrm{u}(\mathrm{LL})}$ values are far too high and not realistic for the transition from the viscous liquid state to the plastic state of remoulded inorganic fine-grained soils and, as such, are not credible values. Two probable explanations for excessively high $s_{\mathrm{u}(\mathrm{LL})}$ values are the following.

- Since they predominantly arose for the silt soils, vane-shear testing of these specimens might have occurred for the

Table 3. Interpolated $S_{\mathrm{u}(\mathrm{LL})}$ values from regression analyses and extrapolation of reported vane $s_{\mathrm{u}}$-water content data by Kayabali and Tufenkci (2010) for 15 inorganic fine-grained soils

\begin{tabular}{|c|c|c|c|c|c|c|c|c|}
\hline \multirow{3}{*}{$\begin{array}{l}\text { Sample } \\
\text { number }\end{array}$} & \multirow{3}{*}{$\begin{array}{l}\text { Soil classification } \\
\text { (BSI, 2015) }\end{array}$} & \multicolumn{2}{|c|}{$W_{\mathrm{L}(\text { cup })}: \%$} & \multicolumn{3}{|c|}{$s_{\mathrm{u}(\mathrm{LL})}$ for mean $w_{\mathrm{L}(\text { cup })}$ value: $\mathrm{kPa}$} & \multicolumn{2}{|c|}{$\begin{array}{l}S_{\mathrm{u}(\mathrm{LL})} \text { for mean } w_{\mathrm{L}(\text { cup })} \times \\
(1+2 \sigma): \mathrm{kPa}\end{array}$} \\
\hline & & \multirow{2}{*}{ Mean } & \multirow{2}{*}{$\begin{array}{l}\text { Standard } \\
\text { deviation, } \sigma\end{array}$} & \multirow{2}{*}{$\begin{array}{l}\text { Reported in } \\
\text { paper }\end{array}$} & \multicolumn{2}{|c|}{$\begin{array}{l}\text { Deduced in present } \\
\text { investigation }\end{array}$} & \multicolumn{2}{|c|}{$\begin{array}{l}\text { Deduced in present } \\
\text { investigation }\end{array}$} \\
\hline & & & & & $\begin{array}{l}\text { Semi-log } \\
\text { approach }\end{array}$ & $\begin{array}{l}\text { Log-log } \\
\text { approach }\end{array}$ & $\begin{array}{l}\text { Semi-log } \\
\text { approach }\end{array}$ & $\begin{array}{l}\text { Log-log } \\
\text { approach }\end{array}$ \\
\hline B-01 & MV & $83 \cdot 6$ & $9 \cdot 5$ & $1 \cdot 8$ & $2 \cdot 1$ & $3 \cdot 1$ & 0.5 & $1 \cdot 3$ \\
\hline B-02 & MV & $77 \cdot 3$ & $4 \cdot 6$ & $4 \cdot 3$ & $4 \cdot 8$ & $6 \cdot 5$ & 1.9 & $3 \cdot 4$ \\
\hline B-03 & $\mathrm{MH}$ & $62 \cdot 4$ & $5 \cdot 1$ & $4 \cdot 2$ & $3 \cdot 5$ & $5 \cdot 0$ & 0.9 & $2 \cdot 1$ \\
\hline B-04 & MV & $79 \cdot 7$ & $7 \cdot 4$ & $12 \cdot 0$ & $13 \cdot 3$ & 14.6 & $4 \cdot 7$ & $7 \cdot 0$ \\
\hline B-05 & $\mathrm{Cl}$ & $46 \cdot 1$ & $1 \cdot 2$ & $1 \cdot 2$ & $1 \cdot 1$ & 1.8 & 0.6 & $1 \cdot 2$ \\
\hline B-06 & $\mathrm{Cl}$ & $37 \cdot 2$ & $2 \cdot 6$ & $1 \cdot 3$ & $1 \cdot 3$ & $2 \cdot 1$ & 0.3 & 0.7 \\
\hline B-07 & CV & $81 \cdot 7$ & $4 \cdot 6$ & 9.0 & $8 \cdot 3$ & 8.9 & $3 \cdot 3$ & $4 \cdot 3$ \\
\hline B-08 & $\mathrm{MH}$ & $64 \cdot 2$ & $2 \cdot 4$ & $6 \cdot 0$ & $5 \cdot 8$ & 6.0 & $2 \cdot 5$ & 2.9 \\
\hline B-09 & $\mathrm{MI}$ & $44 \cdot 3$ & $2 \cdot 7$ & $3 \cdot 8$ & $4 \cdot 7$ & $5 \cdot 3$ & 1.4 & $2 \cdot 0$ \\
\hline B-10 & $\mathrm{Cl}$ & $45 \cdot 7$ & 0.7 & 1.9 & $2 \cdot 3$ & $3 \cdot 4$ & $1 \cdot 8$ & $2 \cdot 8$ \\
\hline B-11 & $\mathrm{CH}$ & $57 \cdot 1$ & $1 \cdot 2$ & $1 \cdot 2$ & $2 \cdot 7$ & $4 \cdot 4$ & $2 \cdot 0$ & $3 \cdot 6$ \\
\hline B-12 & $\mathrm{Cl}$ & $46 \cdot 4$ & $1 \cdot 5$ & 8.0 & 8.9 & $10 \cdot 4$ & $5 \cdot 8$ & $7 \cdot 5$ \\
\hline B-13 & $\mathrm{Cl}$ & $44 \cdot 7$ & 0.6 & $6 \cdot 3$ & $6 \cdot 3$ & $7 \cdot 3$ & $5 \cdot 0$ & $6 \cdot 1$ \\
\hline B-14 & $C L$ & $26 \cdot 4$ & $2 \cdot 7$ & $5 \cdot 8$ & 4.9 & $5 \cdot 1$ & 0.5 & 0.9 \\
\hline \multirow[t]{2}{*}{ B-15 } & $\mathrm{Cl}$ & $37 \cdot 5$ & $2 \cdot 4$ & 6.0 & $5 \cdot 3$ & $5 \cdot 9$ & $1 \cdot 1$ & 1.7 \\
\hline & & \multicolumn{2}{|c|}{ Mean $S_{u(L L)}: k P a$} & 4.9 & $5 \cdot 0$ & $6 \cdot 0$ & $2 \cdot 2$ & $3 \cdot 2$ \\
\hline
\end{tabular}




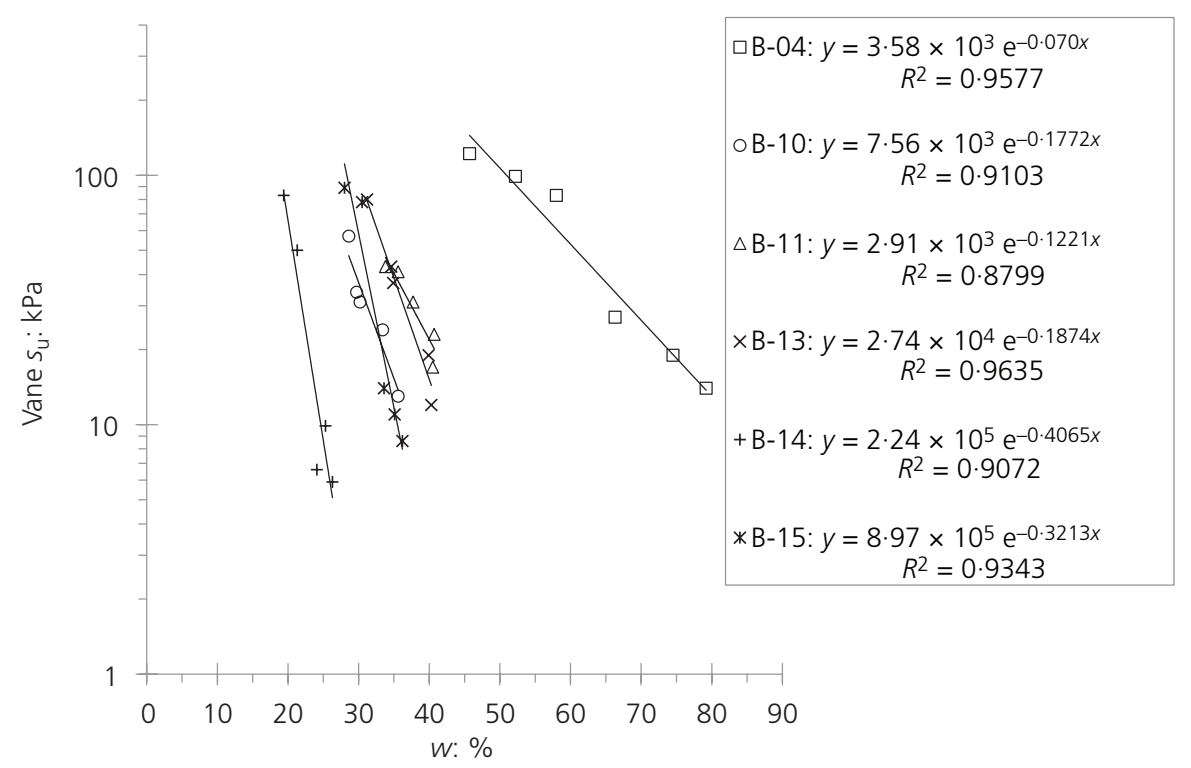

Figure 4. Vane-shear strength against water content relationships for selection of fine-grained soils investigated by Kayabali and Tufenkci (2010). Refer to Table 3 for the $W_{\text {L(cup) }}$ value of each soil sample

partially drained condition, thereby mobilising higher shear strength values compared with most of the clay soils investigated.

- There was much scatter in the reported $s_{\mathrm{u}}-w$ data for a given soil when presented in a semi-logarithmic chart, as evident from Figure 4. Given that the data set for each soil investigated was comprised of only five to seven $s_{\mathrm{u}}-w$ data pairs, a 'stray' strength value could significantly and adversely influence the interpolated value for $s_{\mathrm{u}(\mathrm{LL})}$. For instance, extrapolation of the best-fit lines to the data set for soil sample B-13 (comprising five data pairs) and the same data set but excluding the data point for $w=39 \cdot 9 \%$ (see Figure 5) produces deduced $s_{\mathrm{u}(\mathrm{LL})}$ values of $8 \cdot 0$ and $4.8 \mathrm{kPa}$, respectively, for this clay material.

Another possibility is that, for some of the silt soils, the paste samples could have tended to slide on the inner surface of the Casagrande cup, resulting in the pre-cut groove closing, rather than the requirement for flow taking place within the soil samples themselves. Furthermore, as evident from Figure 2, the Kayabali and Tufenkci (2010) data set does not exhibit the characteristic trend shown experimentally in the papers by Youssef et al. (1965) and Haigh (2016) of $s_{\mathrm{u}(\mathrm{LL})}$ reducing approximately linearly in value with increasing $w_{\mathrm{L}(\text { cup) }}$ when presented in a bi-logarithmic chart. Instead, the regression line to the mean $w_{\mathrm{L}(\mathrm{cup})}$ and $s_{\mathrm{u}(\mathrm{LL})}$ data pairs reported for the 15 fine-grained soils investigated by Kayabali and Tufenkci (2010) suggests a trend of $s_{\mathrm{u}(\mathrm{LL})}$ increasing in value with increasing $w_{\mathrm{L}(\mathrm{cup})}$, which is not possible (Haigh, 2016).

Other features of the Kayabali and Tufenkci (2010) data set are that all of the vane-shear strength measurements were for $w<$ $w_{\mathrm{L} \text { (cup), }}$ with the lowest measured shear strength value for eight of

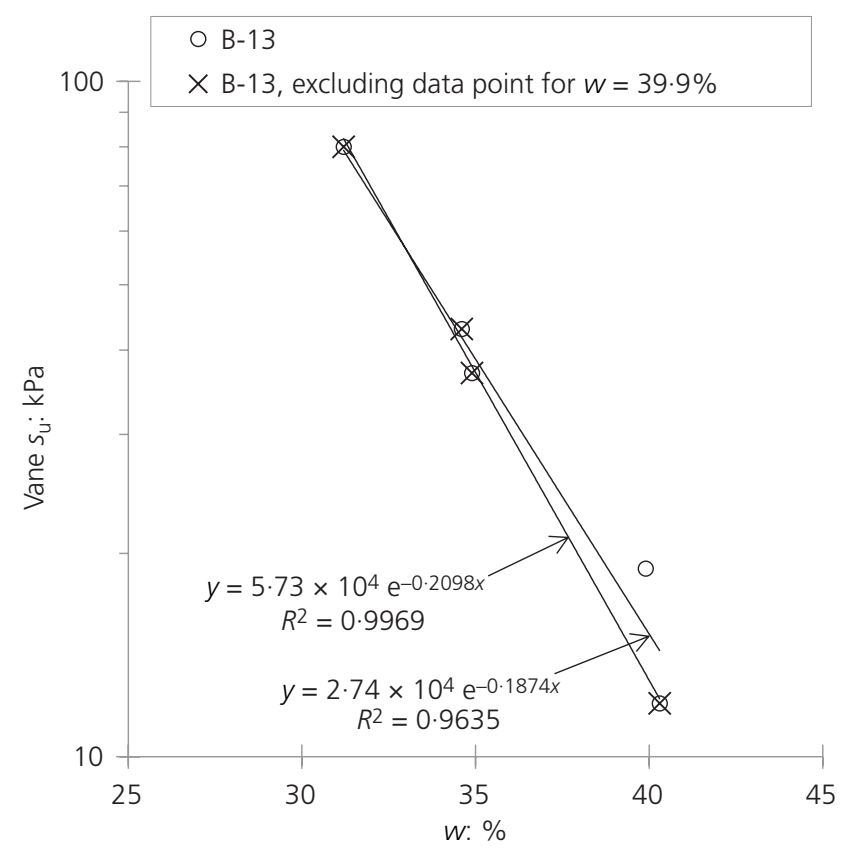

Figure 5. Vane-shear strength against water content relationships for clay soil sample B-13 $\left(W_{\mathrm{L} \text { (cup })}=44 \cdot 7 \%\right)$ investigated by Kayabali and Tufenkci (2010)

the 15 soils investigated ranging $12-19 \mathrm{kPa}$, while the lowest measured shear strength value reported for their entire data set was $5 \mathrm{kPa}$. The absence of strength-measurement data for water contents about the LL may be regarded as a shortcoming of their investigation, and, ideally, a couple of strength measurements should also have been obtained for $w>w_{\mathrm{L} \text { (cup) }}$. 


\section{Wasti and Bezirci (1986)}

Wasti and Bezirci (1986) reported values of $w_{\mathrm{L}(\mathrm{cup})}$ and vane $s_{\mathrm{u}(\mathrm{LL})}$ for 15 natural and ten artificial clay soils, with the latter prepared by mixing various proportions of bentonite material with some of the natural soil samples. The LL values were determined using a Casagrande-cup device with a hard-base material (code of practice not reported). Shear strength tests were performed on remoulded specimens prepared at various water contents covering the soils' plastic ranges using a $12.7 \mathrm{~mm}$ high $\times 12.7 \mathrm{~mm}$ wide vane that was rotated at an angular rotation rate of $60 \% \mathrm{~min}$, considered sufficiently fast for undrained shearing of these clay specimens. Additionally, a comparison of $s_{\mathrm{u}}$ values as measured by vane shear and $30^{\circ}-80 \mathrm{~g}$ fall-cone testing was presented for four of these clay soils. Values of $s_{\mathrm{u}(\mathrm{LL})}$ ranging $0 \cdot 5-5 \cdot 6 \mathrm{kPa}$ were interpolated from plots of liquidity index $\left(I_{\mathrm{L}}\right)$ against vane $s_{\mathrm{u}}$ presented on a logarithmic scale. The number of vane-shear tests performed for each soil investigated and their repeatability were not reported.

Only the deduced vane $s_{\mathrm{u}}$ against water content or $I_{\mathrm{L}}$ relationships (but not the actual vane $s_{\mathrm{u}}$ data points) are shown in various plots presented in the Wasti and Bezirci (1986) paper for 24 of the 25 clay soils investigated. As such, it is not possible to perform an independent analysis of their $s_{\mathrm{u}}-w$ data as part of the present investigation. However, there are some apparent inconsistencies, for instance, between the presented vane-shear relationship and the fall-cone data points for soil sample number 6 (see Figure 6(a)), one of four soils investigated for which both of these strength tests were performed. Based on the vane shear strength data, Wasti and Bezirci (1986) reported that the value of $s_{\mathrm{u}(\mathrm{LL})}$ for this particular soil was $5.6 \mathrm{kPa}$, which happens to be one of the outliers (and upper-bound value: see Figure 2) of their $s_{\mathrm{u}(\mathrm{LL})}$ data set for the 24 clay soils investigated. Although the results of different shear strength tests are not expected to correspond precisely (O'Kelly, 2013b, 2013c, 2014a), compared to the fall cone, the $I_{\mathrm{L}}$-vane $s_{\mathrm{u}}$ relationship presented in Figure 6(a) shows an apparent sharp deviation for water content values close to the LL (i.e. values of $I_{\mathrm{L}}$ close to unity), with interpolation of the fall-cone data instead suggesting a more plausible $s_{\mathrm{u}(\mathrm{LL})}$ value of $3 \cdot 1 \mathrm{kPa}$ for this particular soil. Again, based on the vane-shear strength data, Wasti and Bezirci (1986) reported an $s_{\mathrm{u}(\mathrm{LL})}$ value for soil sample number 19 of $0.72 \mathrm{kPa}$, which happens to be one of the lower-bound values of their $s_{\mathrm{u}(\mathrm{LL})}$ data set (see Figure 2). Referring to the reported $I_{\mathrm{L}}$-vane $S_{\mathrm{u}}$ relationship for soil sample number 19 presented in Figure 6(b), this strength value cannot be substantiated and a vane $S_{\mathrm{u}(\mathrm{LL})}$ value of approximately $1.1 \mathrm{kPa}$ seems more appropriate. For the other two soils (i.e. sample numbers 11 and 16 with $w_{\mathrm{L}(\mathrm{cup})}$ values of 110 and $526 \%$, respectively), the agreement between the presented vane-shear relationship and fall-cone data were quite satisfactory, with reported vane $s_{\mathrm{u}(\mathrm{LL})}$ values of 2.0 and $0.9 \mathrm{kPa}$, respectively, which are more in line with that expected according to the experimental vane $s_{\mathrm{u}(\mathrm{LL})}-w_{\mathrm{L}(\text { cup })}$ correlation after the paper by Youssef et al. (1965).

Furthermore, the semi-logarithmic $I_{\mathrm{L}}-S_{\mathrm{u}}$ presentation of the data for the natural and artificial clay soils appearing in the Wasti and Bezirci (1986) paper appears as a convenient way of reporting the data for all 24 soils investigated. However, compared to an $s_{\mathrm{u}}-w$ (or a $w-s_{\mathrm{u}}$ ) plot, this approach is not as accurate (reliable) in terms of performing strength interpolations for specified water content values (in this case $w_{\mathrm{L} \text { (cup) }}$ ) for the following reasons. First, the Casagrande LL test and in particular the thread-rolling PL test may have poor repeatability (Belviso et al., 1985; Sherwood, 1970; Sherwood and Ryley, 1970; Whyte, 1982). As reported, it appears that only single Casagrande LL and PL tests were performed for each soil investigated by Wasti and Bezirci (1986), compared, for instance, to the 15 Casagrande LL and PL tests performed for each soil investigated in the previously discussed Kayabali and Tufenkci (2010) investigation. Because of its form, the exponential $I_{\mathrm{L}}$ against $s_{\mathrm{u}}$ relationship can be particularly sensitive to any inaccuracy in the determination of the experimental $I_{\mathrm{L}}$ values; that is, accentuating any inaccuracies in

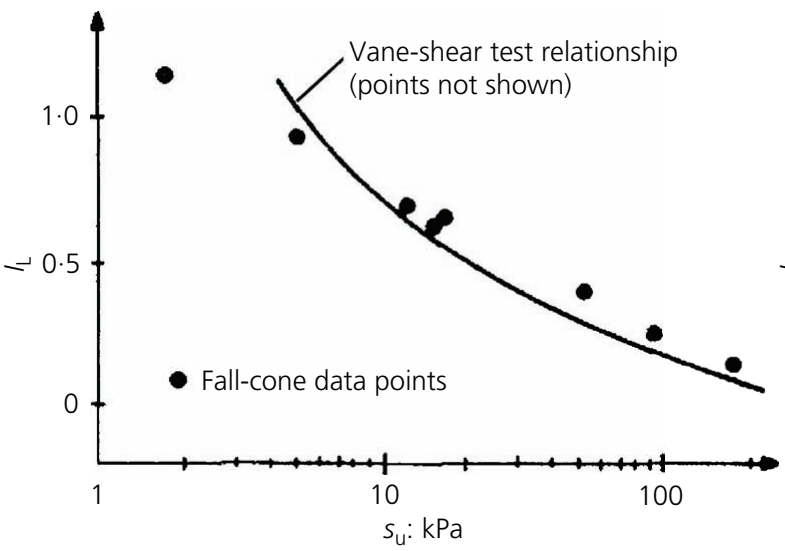

(a)

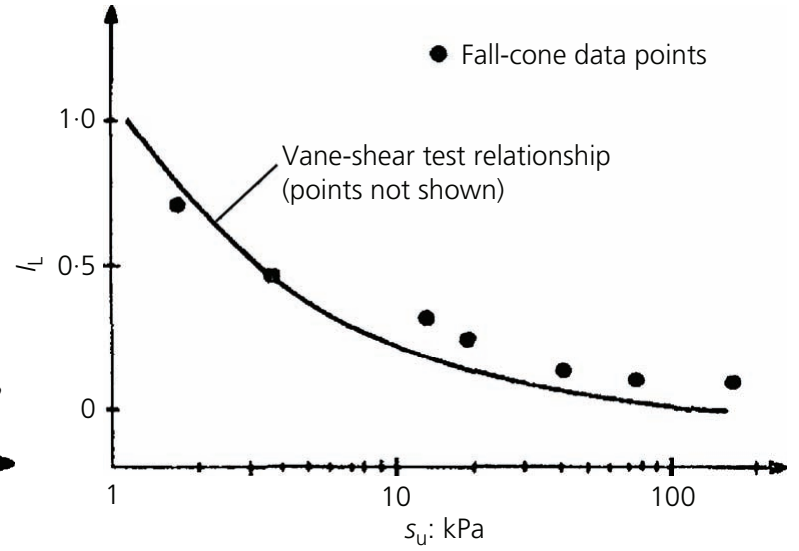

(b)

Figure 6. Comparison of vane-shear relationship and fall-cone strength values for two clay soils (part reproduction of figure 7 presented in the paper by Wasti and Bezirci (1986)): (a) sample number 6 ( $\left.W_{\text {L(cup })}=52 \%, w_{P}=22 \%\right)$; (b) sample number $19\left(w_{\text {L(cup })}=196 \%, w_{P}=23 \%\right)$ 
Fallacy of wide undrained strength range

at the Casagrande liquid limit

O'Kelly

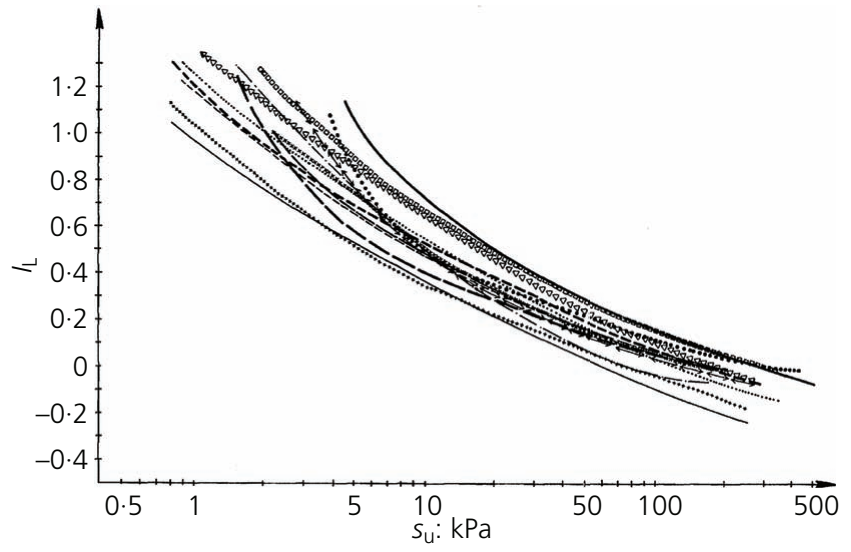

Figure 7. Liquidity index against vane-shear strength relationships for 15 natural clay soils with $W_{\mathrm{L}(\text { cup })}=27-526 \%$ and $w_{\mathrm{P}}=$ 17-39\% (adopted from Wasti and Bezirci (1986))

the consistency limit measurements, as acknowledged by Wasti and Bezirci (1986). Further, as evident from Figures 6 and 7, the semi-logarithmic $I_{\mathrm{L}}-S_{\mathrm{u}}$ data plots can be highly non-linear, particularly close to the LL (i.e. $I_{\mathrm{L}}=1 \cdot 0$ ). As such, linear extrapolation of the $I_{\mathrm{L}}-S_{\mathrm{u}}$ regression lines to estimate $s_{\mathrm{u}}$ values for water contents close to and corresponding to the LL may produce (highly) misleading results (Wroth and Wood, 1978) and a bilogarithmic presentation of the experimental data may have been more appropriate, given the very wide range of soil plasticity (Butterfield, 1979; O’Kelly, 2014a).

Overall, as evident from Figure 2, the Wasti and Bezirci (1986) data set reasonably follows (but is tending on the high side of) the bi-logarithmic $s_{\mathrm{u}(\mathrm{LL})}-w_{\mathrm{L}(\mathrm{cup})}$ correlation line after the paper by Youssef et al. (1965). The mean $s_{\mathrm{u}(\mathrm{LL})}$ values for the 15 natural
$\left(w_{\mathrm{L}(\text { cup })}=27-110 \%\right)$ and ten artificial $\left(w_{\mathrm{L}(\text { cup })}=145-526 \%\right)$ soil samples were 2.7 and $1.4 \mathrm{kPa}$, respectively - with a mean $s_{\mathrm{u}(\mathrm{LL})}$ value of $2 \cdot 15 \mathrm{kPa}$ computed for the 24 soils investigated. In terms of the $w_{\mathrm{L}(\mathrm{cup})}$ range of $32-190 \%$ considered in the Youssef et al. (1965) investigation, the subset of the Wasti and Bezirci (1986) data set covering the comparable $w_{\mathrm{L}(\mathrm{cup})}$ range of $27-196 \%$ has a mean $s_{\mathrm{u}(\mathrm{LL})}$ value of $2.4 \mathrm{kPa}(n=19)$, which again is on the high side compared to the average value of around $1.6-1 \cdot 7 \mathrm{kPa}$ generally associated with Casagrande LL (Sharma and Bora, 2003; Whyte, 1982; Wroth and Wood, 1978; Youssef et al., 1965). However, ignoring what appear as obvious outliers (i.e. $s_{\mathrm{u}(\mathrm{LL})}$ $<0.7$ and $>2.9 \mathrm{kPa}$ ) produces an average $s_{\mathrm{u}(\mathrm{LL})}$ value of $1.7 \mathrm{kPa}$ $\left(n=13\right.$ ) for the same $w_{\mathrm{L}(\text { cup) }}$ range of $27-196 \%$, in agreement with the general consensus $s_{\mathrm{u}(\mathrm{LL})}$ value of around $1 \cdot 6-1 \cdot 7 \mathrm{kPa}$.

An interesting inclusion in the Wasti and Bezirci (1986) data set is the ratio of the $I_{\mathrm{P}}$ value to the percentage of clay-size particles present for each soil investigated - that is, their activity values, which reflect the degree of plasticity of their clay-size fraction. In this section, the author explores possible inter-relationships between the activity of the clay minerals present, the measured consistency limits and associated shear strength values deduced for the different soils. For the purposes of this analysis, soil sample numbers 3, 12-16 and 25 comprising the Wasti and Bezirci (1986) data set were excluded (as one or more of their reported vane $s_{\mathrm{u}}$ values were considered unreliable), while the values of $s_{\mathrm{u}(\mathrm{LL})}$ for soil sample numbers 6 and 19 were changed to $3 \cdot 1$ and $1 \cdot 1 \mathrm{kPa}$, respectively, for the reasons explained earlier. As expected (e.g. see O'Kelly (2014c)), the values of $w_{\mathrm{L} \text { (cup) }}$ and $I_{\mathrm{P}}$ were both found to increase substantially with increasing activity value (Figure 8(a)).

Further, the values of vane $s_{\mathrm{u}(\mathrm{LL})}$ reduced with increasing soil activity (Figure 8(b)), with an exponential decrease implied, akin

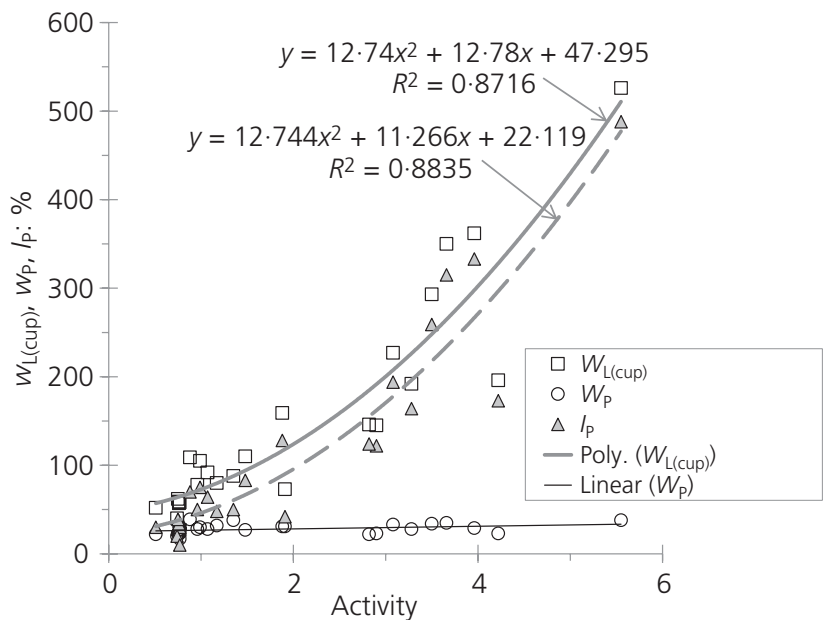

(a)

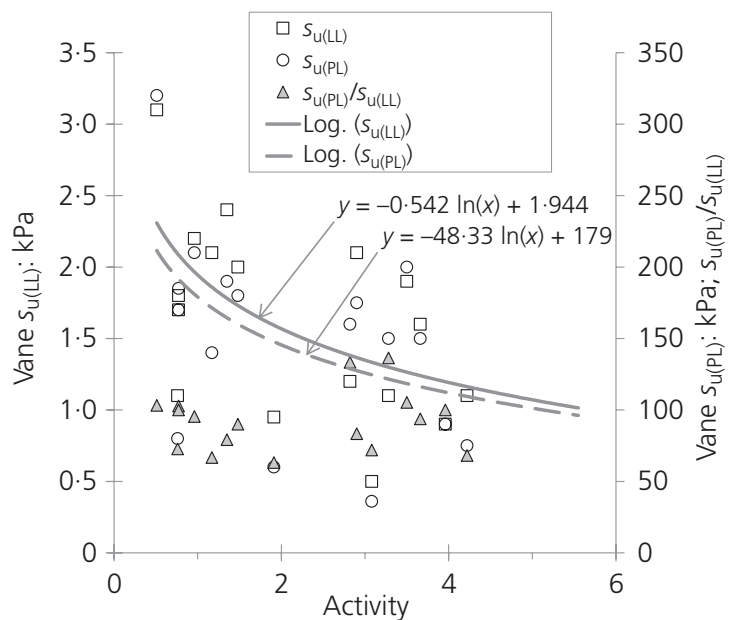

(b)

Figure 8. Effects of soil activity on (a) consistency limits and plasticity index and (b) associated vane-shear strengths and the strength gain ratio for the full plastic range (data after Wasti and Bezirci (1986)) 
to the bi-logarithmic $s_{\mathrm{u}(\mathrm{LL})}$ against $w_{\mathrm{L}(\text { cup })}$ inverse correlations reported in the papers by Haigh (2016) and Youssef et al. (1965). High-plasticity soil has a lower soil density for a given water content value, and with $w_{\mathrm{L}(\text { cup) }}$ corresponding to an $S_{\mathrm{s}}$ value of $\sim 1 \cdot 0 \mathrm{~m}^{2} / \mathrm{s}^{2}$ (Haigh, 2012), its value of $s_{\mathrm{u}(\mathrm{LL})}$ must be inferior compared to that of low-plasticity soil. In other words, higher activity correlates with greater plasticity, higher $w_{\mathrm{L}(\text { cup) }}$ values and lower $s_{\mathrm{u}(\mathrm{LL})}$ values. Referring to Figure $8(\mathrm{~b})$, the values of remoulded vane undrained shear strength corresponding to the reported $w_{\mathrm{P}}$ values (i.e. $s_{\mathrm{u}(\mathrm{PL})}$ ) were also found to reduce in value with increasing activity, suggesting that clay mineralogy is one of the material factors controlling shear strength at the PL. Based on the ratio of the author's deduced $s_{\mathrm{u}(\mathrm{PL})}$ to $s_{\mathrm{u}(\mathrm{LL})}$ values, the gain factor $\left(R_{\mathrm{S}}\right)$ in undrained shear strength considering the full plastic range varied from 63 to 136 , with a computed mean $R_{\mathrm{s}}$ value of $92(\sigma=21$ for $n=17)$, in close agreement with the reported mean $R_{\mathrm{S}}$ value of 90 by Wasti and Bezirci (1986) considering the data for all 24 soils investigated. Based on the data presented in Figure $8(\mathrm{~b})$, there is no strong trend to suggest that the $R_{\mathrm{S}}$ value is influenced by the soil activity (clay mineralogy).

\section{Vinod et al. (2013a)}

A more recent paper reporting excessively high measured and interpolated values of $s_{\mathrm{u}(\mathrm{LL})}$ is the Vinod et al. (2013a) investigation, which examined the vane $s_{\mathrm{u}}-I_{\mathrm{L}}$ relationships for nine different fine-grained soils that included pure kaolinite and bentonite materials. Together, the test soils covered the LL and $I_{\mathrm{P}}$ ranges $37-234$ and $11-180 \%$, respectively. For the purposes of the analysis, the test soils were categorised into four soil groupings, namely $\mathrm{CL}, \mathrm{ML}, \mathrm{CH}$ and $\mathrm{MH}$, according to the Unified Soil Classification System (ASTM, 2017b). For LL determination, Vinod et al. (2013a) employed the Casagrande-cup method for the pure bentonite soil material and two very or extremely high-plasticity soils that they investigated, whereas the fall-cone method was adopted for the pure kaolinite soil material and five intermediate- or high-plasticity soils investigated. They rationalised this approach on the basis that there are good agreements between the mechanism controlling the LL of bentonite soils and the dominant mechanism in the Casagrandecup method (i.e. viscous shear resistance due to diffuse doublelayer water) and also between the mechanism controlling the LL of kaolinitic soils and the dominant mechanism in the fall-cone method (i.e. frictional resistance at the particle level), as described by Sridharan and Prakash (1998). The codes of practice adopted for the LL testing, including details of the cone's mass and apex angle, the cone penetration depth value defining the fall-cone LL (which together with the assumed value of the cone factor $(K)$ determine the associated $s_{\mathrm{u}}$ value for the fall-cone LL) and whether the Casagrande-cup device had a hard- or softer-base material, were not stated. The reported $w_{\mathrm{P}}$ values were determined using the standard thread-rolling method. Within the identified plastic range for each soil, vane-shear tests were performed for four different water content values in accordance with ASTM D 4648-10 (ASTM, 2010). All data for each of the four soil groupings described earlier were assembled on separate semi- logarithmic charts of $I_{\mathrm{L}}$ against vane $s_{\mathrm{u}}$ (see Figure 9) and regression analysis performed to determine the values of the two empirical parameters, $a$ and $b$, used to define their exponential relationships.

1. $I_{\mathrm{L}}=a \mathrm{e}^{-b s_{\mathrm{u}}}$

In practice, however, each soil has its unique $I_{\mathrm{L}}-s_{\mathrm{u}}$ correlation (e.g. see Figure 7), such that the values of the $a$ and $b$ parameters are soil dependent. Further, as reported in the papers by Haigh et al. (2013), Nagaraj et al. (2012) and O'Kelly (2013a), the value of $s_{\mathrm{u}(\mathrm{PL})}$ (i.e. for $I_{\mathrm{L}}=0$ ) can vary widely between different finegrained soils. As such, it seems inappropriate to assess the values of $s_{\mathrm{u}}$ at the consistency limits based on a combined data set assembled for a number of different fine-grained soils, albeit that they belonged to the same soil group classification. Nevertheless, using their deduced $I_{\mathrm{L}}-S_{\mathrm{u}}$ relationships, Vinod et al. (2013a) backcalculated a mean $s_{\mathrm{u}(\mathrm{LL})}$ value of $5 \cdot 8 \mathrm{kPa}$, with a range $5 \cdot 3-7 \cdot 0 \mathrm{kPa}$ evident in the data spread at $I_{\mathrm{L}}=1 \cdot 0$ (i.e. at the LL) for all nine soils presented in Figure 9. However, these back-calculated $s_{\mathrm{u}(\mathrm{LL})}$ values are unrealistically high, given, as cited by Vinod et al. (2013a: p. 416), Narain and Ramanathan (1970) described the LL as 'the extreme limiting water content above which the forces of interaction between particles become sufficiently weak to allow easy movement of the particles relative to each other'.

To contextualise these reported $s_{\mathrm{u}(\mathrm{LL})}$ values, the expected $S_{\mathrm{S}}$ value of $\sim 1.0 \mathrm{~m}^{2} / \mathrm{s}^{2}$ corresponding to $w_{\mathrm{L} \text { (cup) }}$ (Haigh, 2012) might imply an $s_{\mathrm{u}(\mathrm{LL})}$ range for the investigated fine-grained soils of $1 \cdot 41-1 \cdot 76 \mathrm{kPa}$ according to the analysis presented by Vinod et al. (2013b), while an $s_{\mathrm{u}}$ value of $\sim 1.7 \mathrm{kPa}$ might be expected for standard fall-cone LL approaches (Wroth and Wood, 1978). Vinod et al. (2013b) themselves recognised that, compared to

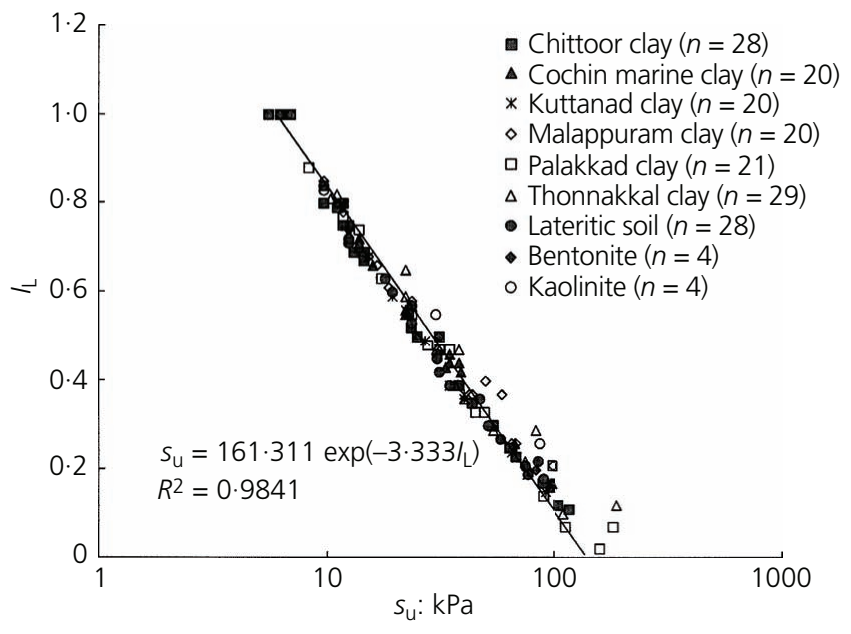

Figure 9. Liquidity index against vane-shear strength data plots for intermediate to extremely high-plasticity soils (adopted from Vinod et al. (2013a)) 
the vast majority of the published experimental evidence (see Table 1), their deduced $s_{\mathrm{u}(\mathrm{LL})}$ values were very high, which they postulated may be due to either limitations of their vane-shear testing method near the LL water contents or (more likely) inadequate sensitivity in $s_{\mathrm{u}}$ determinations for water contents close to the LL. In practice, the measurement sensitivity can be improved by fitting a cruciform vane of larger dimensions and/or a weaker torsion spring in the head assembly of the vane-shear apparatus. Another observation is that a much wider $s_{\mathrm{u}(\mathrm{PL})}$ range than the back-calculated range $146-188 \mathrm{kPa}$ (mean of $161 \mathrm{kPa}$ ) reported by Vinod et al. (2013b) may generally be expected for fine-grained soils (Barnes and O'Kelly, 2011; Haigh et al., 2013; Nagaraj et al., 2012; O'Kelly, 2013a). Other possible shortcomings of their analysis may include the following.

- Typically only four vane-shear tests were performed over the plastic range of each soil investigated, with no $s_{\mathrm{u}}$ measurements obtained for water contents greater that the LL.

- By analysing their data in terms of $I_{\mathrm{L}}$ (rather than simply water content), measurement inaccuracies for the consistency limits are compounded.

- Some curvature inevitably occurs for semi-logarithmic $I_{\mathrm{L}}-S_{\mathrm{u}}$ data plots (most evident e.g. in the case of the data for Thonnakkal clay material presented in Figure 9), which often cannot be adequately captured by the employed linear regression-analysis approach.

\section{Discussion}

The LL, as originally proposed by Atterberg (1911a, 1911b), introduced into soil mechanics by Terzaghi (1926a, 1926b) and with the associated percussion-cup test method for its determination standardised by Casagrande (1932), is notionally the water content below which the soil would cease to flow as a liquid. Since this transition does not correspond to a sudden definite change in soil behaviour, codes of practice for $w_{\mathrm{L} \text { (cup) }}$ determinations essentially define the LL in terms of the water content value associated with an arbitrarily chosen, small but recognisable $S_{\mathrm{s}}$ value. Explicitly, as evident in Figure 10(a),

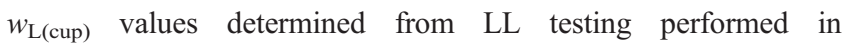
accordance with ASTM D 4318-17e1 (ASTM, 2017a) or BS 1377-2:1990 (BSI, 1990) and employing compliant Casagrandecup devices correspond to $S_{\mathrm{s}}$ values of $\sim 1 \cdot 0 \mathrm{~m}^{2} / \mathrm{s}^{2}$ (Haigh, 2012). Haigh (2016) demonstrated that considering potential degradation of device base materials may occur over time, both base hardness and resilience must be regularly monitored (as mandated by ASTM (2017a)) in order to ensure proper device performance and thereby achieve consistency of $w_{\mathrm{L}(\mathrm{cup})}$ test results.

For soil plasticity increasing from low to very high levels (i.e. $20 \% \leq w_{\mathrm{L}(\text { cup })} \leq 70 \%$ ), based on the $w_{\mathrm{L}(\text { cup })}-S_{\mathrm{u}(\mathrm{LL})}$ data pairs presented for 69 different fine-grained soils in the papers by Campbell (1975), Leroueil and Le Bihan (1996), Norman (1958), Sherwood and Ryley (1970) and Youssef et al. (1965) (these data

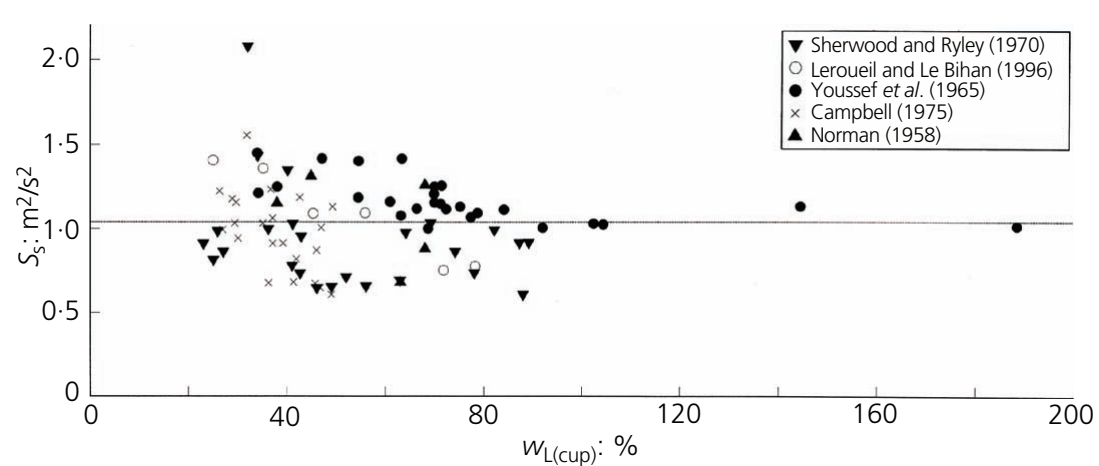

(a)

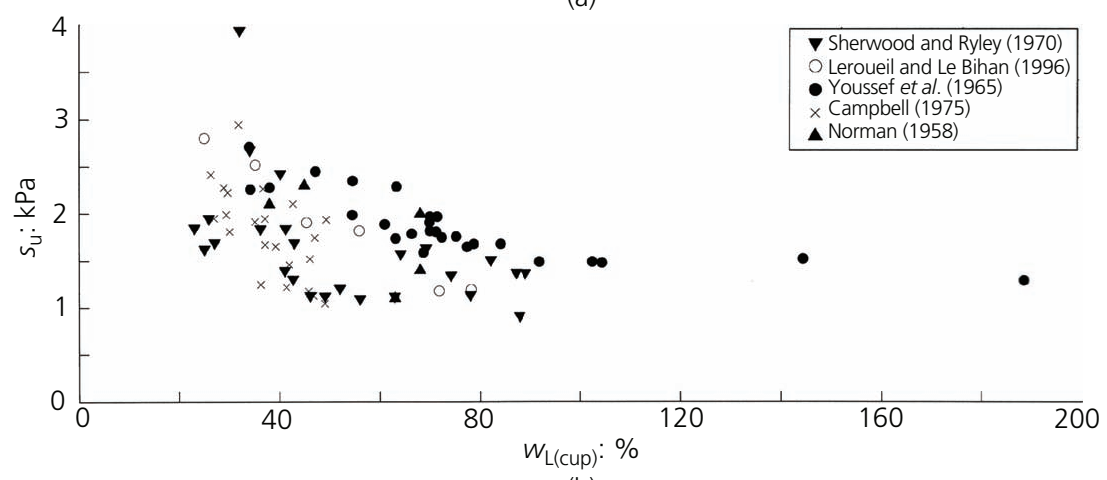

(b)

Figure 10. Strength variation with $w_{\mathrm{L}(\mathrm{cup})}$ (adopted from Haigh (2012)): (a) specific strength; (b) undrained shear strength 
are summarised in Figure 10(b)) and also the paper by Das et al. (2013), the author has deduced the following.

The average $S_{\mathrm{s}}$ value of $\sim 1 \cdot 0 \mathrm{~m}^{2} / \mathrm{s}^{2}$, considering both classes of Casagrande-cup devices, equates to the value of $s_{\mathrm{u}(\mathrm{LL})}$ decreasing from approximately 2.5 to $1.6 \mathrm{kPa}$, with all bar one of the 69 data points falling within the narrow $s_{\mathrm{u}(\mathrm{LL})}$ range of $1-3 \mathrm{kPa}$. The exception was $s_{\mathrm{u}(\mathrm{LL})}=3.9 \mathrm{kPa}$ for $w_{\mathrm{L}(\mathrm{cup})} \approx 32 \%$, reported in the paper by Sherwood and Ryley (1970).

This analysis is consistent with the best-fit $w_{\mathrm{L}(\text { cup })}-S_{\mathrm{u}(\mathrm{LL})}$ power relationship reported in the paper by Youssef et al. (1965), which predicts that Casagrande $s_{\mathrm{u}(\mathrm{LL})}$ decreases from approximately 2.7 to $1.7 \mathrm{kPa}$ for the same $w_{\mathrm{L}(\text { cup })}$ range covered by the database of 69 different fine-grained soils. As mentioned earlier, compared to the BSI code (BSI, 1990), the ASTM (2017a)-compliant Casagrande-cup device, with its harder-base material, produces a lower $w_{\mathrm{L}(\text { cup) }}$ value for a given fine-grained soil (Haigh, 2016; Norman, 1958; Sridharan and Prakash, 2000; Whyte, 1982) and hence a marginally higher $S_{\text {ua(LL) }}$ value. The latter is reflected in their respective $S_{\mathrm{s}}$ values of $\sim 0.94$ and $1.07 \mathrm{~m}^{2} / \mathrm{s}^{2}$ reported by Haigh (2012). Further, the definition of the LL, as determined using the British standard (BSI, 1990) and Swedish (e.g. Karlsson, 1961) fall-cone LL approaches, equates to mobilised $s_{\mathrm{u}}$ values of $\sim 1 \cdot 7 \mathrm{kPa}$ (Wroth and Wood, 1978), which is essentially independent of the level of soil plasticity. Thence, the overwhelming weight of experimental evidence indicates that with $w_{\mathrm{L} \text { (cup) }}$ determined using Casagrande-cup devices compliant with either the ASTM or BSI code, 1.0 and $3.0 \mathrm{kPa}$ represent lowerand upper-bound values for Casagrande $s_{\mathrm{u}(\mathrm{LL})}$ in the case of low- to very high-plasticity inorganic fine-grained soils.

It is not tenable, therefore, that fine-grained soil at its $w_{\mathrm{L} \text { (cup) }}$ water content value could mobilise $s_{\mathrm{u}(\mathrm{LL})}$ values of, say, $5.6 \mathrm{kPa}$, $12 \mathrm{kPa}$ or a mean of $5.8 \mathrm{kPa}$, as was reported in the papers by Wasti and Bezirci (1986), Kayabali and Tufenkci (2010) and Vinod et al. (2013a), respectively. Simply stated, using an extreme example of the remoulded B-04 silt soil sample investigated in the paper by Kayabali and Tufenkci (2010), its transition from a viscous liquid state to a plastic state could not occur for an $s_{\mathrm{u}(\mathrm{LL})}$ value of $12 \mathrm{kPa}$. In their investigations, the undrained shear strength value associated with the LL was reduced to a curve-fitting (regression analysis) exercise, such that the true definition and meaning of the LL, as originally set out by Atterberg (1911a, 1911b), appear to have been somewhat overlooked in the cases of a few soil samples they investigated.

Grossly inaccurate values of Casagrande $s_{\mathrm{u}(\mathrm{LL})}$ can be deduced for a variety of reasons, including the following.

- Inexperienced operator, not adhering to the procedures in codes and/or using a non-compliant Casagrande-cup device.

v The shear strength apparatus employed may not have the required measurement sensitivity for the very low $s_{\mathrm{u}}$ values mobilised for water contents about the LL, and/or the specimen shearing rate may be too slow to maintain a truly undrained condition.

- An insufficient number of $s_{\mathrm{u}}$ measurements are obtained, and/ or a couple of $s_{\mathrm{u}}$ measurements for $w>w_{\mathrm{L}(\text { cup) }}$ are absent, which may adversely impact on the accuracy of the results from the $s_{\mathrm{u}}-w$ regression analysis.

- The curve-fitting approach adopted for interpolation of the $s_{\mathrm{u}(\mathrm{LL})}$ value from the obtained $s_{\mathrm{u}}-w$ data pairs may not be the most appropriate; for instance, compared to semi-logarithmic, bi-logarithmic $s_{\mathrm{u}}-w$ regression analysis is often preferable, with both of these approaches recommended over semilogarithmic $s_{\mathrm{u}}-I_{\mathrm{L}}$.

As evident from the data set reported by Kayabali and Tufenkci (2010) for 15 low- to very high-plasticity clay and silt materials (see also Table 3 ), their deduced $s_{\mathrm{u}(\mathrm{LL})}$ values of $>4 \mathrm{kPa}$ are generally not specific to either clay or silt materials or particularly accentuated for certain levels of soil plasticity. As described earlier, a possible exception relates to silt materials for which the specimen shearing rate employed must be fast enough to maintain a truly undrained condition. In other words, it is well known that vane shear is most suitable and effective for clay soils. Undrained shear strength determinations from vane-shear testing for others soils may produce inaccurate values.

\section{Summary and conclusions}

The LL is notionally the transitional water content below which fine-grained soil would cease to flow as a liquid. The values of the LL water content (i.e. $w_{\mathrm{L} \text { (cup) }}$ ), as determined for fine-grained soils using ASTM and BSI Casagrande-cup devices, correspond to an $S_{\mathrm{s}}$ value of $\sim 1.0 \mathrm{~m}^{2} / \mathrm{s}^{2}$, such that the value of Casagrande $s_{\mathrm{u}(\mathrm{LL})}$ reduces with increasing $w_{\mathrm{L}(\text { cup })}$. For low- to very highplasticity soils, the overwhelming weight of experimental evidence indicates that the value of Casagrande $s_{\mathrm{u}(\mathrm{LL})}$ can range $1-3 \mathrm{kPa}$, but typically decreases from approximately 2.5 to $1.6 \mathrm{kPa}$ for $w_{\mathrm{L}(\text { cup })}$ increasing from 20 to $70 \%$.

The value of $w_{\mathrm{L} \text { (cup) }}$ measured for a given fine-grained soil is somewhat dependent on the class of Casagrande-cup device employed (i.e. hard- or softer-base material), with regular monitoring of both base hardness and resilience mandated to achieve consistency of test results. The associated $s_{\mathrm{u}(\mathrm{LL})}$ value is dependent on the number and accuracy of $s_{\mathrm{u}}$ measurements obtained at various water contents for the plastic and slurry material states, as well as the curve-fitting approach adopted for its interpolation from regression analysis. A semi- or bilogarithmic $s_{\mathrm{u}}-w$ presentation of the experimental data is generally preferred, with the latter approach more appropriate when considering a wide water content range, although caution is required in the case of some bentonite soils for which the $s_{\mathrm{u}}-w$ data plots may exhibit bilinear type relationships. Further, the shear strength apparatus employed must have the required measurement sensitivity and the shearing rate must be sufficiently fast to maintain a truly undrained specimen condition. It is also 
well known that undrained shear strength determinations from vane-shear testing for silt soils may produce inaccurate values.

As was the case for some fine-grained soils investigated in the papers by Kayabali and Tufenkci (2010), Vinod et al. (2013a) and Wasti and Bezirci (1986), grossly inaccurate (superhigh) values of Casagrande $s_{\mathrm{u}(\mathrm{LL})}$ can be deduced for a variety of reasons, including an insufficient number of $s_{\mathrm{u}}-w$ data pairs and/or absence of a couple of $s_{\mathrm{u}}$ measurements at $w>w_{\mathrm{L}(\mathrm{cup})}$ for each soil investigated; insufficient measurement sensitivity of the shear strength apparatus employed and/or the soil specimens are sheared at too slow a rate, thereby allowing them to drain partially; and (or) inappropriate semi-logarithmic $s_{\mathrm{u}}-I_{\mathrm{L}}$ curvefitting approach adopted for interpolation of the $s_{\mathrm{u}(\mathrm{LL})}$ value.

\section{REFERENCES}

ASTM (2000) D 4318-00: Standard test methods for liquid limit, plastic limit, and plasticity index of soils. ASTM International, West Conshohocken, PA, USA.

ASTM (2010) D 4648-10: Standard test method for laboratory miniature vane shear test for saturated fine-grained clayey soil. ASTM International, West Conshohocken, PA, USA.

ASTM (2017a) D 4318-17e1: Standard test methods for liquid limit, plastic limit, and plasticity index of soils. ASTM International, West Conshohocken, PA, USA.

ASTM (2017b) D 2487-17: Standard practice for classification of soils for engineering purposes (Unified Soil Classification System). ASTM International, West Conshohocken, PA, USA.

Atterberg A (1911a) Die Plastizität der Tone. Internationale Mitteilungen der Bodenkunde 1: 4-37 (in German).

Atterberg A (1911b) Lerornas forhållande till vatten, deras plasticitetsgränser och plasticitetsgrader. Kungliga Lantbruksakademiens Handlingar och Tidskrift 50(2): 132-158 (in German).

Barnes GE and O'Kelly BC (2011) Discussion: An apparatus for the plastic limit and workability of soils. Proceedings of the Institution of Civil Engineers - Geotechnical Engineering 164(4): 293-294, https://doi. org/10.1680/geng.2011.164.4.293.

Belviso R, Ciampoli S, Cotecchia V and Federico A (1985) Use of cone penetrometer to determine consistency limits. Ground Engineering 18(5): $21-22$

BSI (1990) BS 1377-2:1990: Methods of test for soils for civil engineering purposes (classification tests). BSI, London, UK.

BSI (2015) BS 5930:2015: Code of practice for ground investigations. BSI, London, UK.

Butterfield R (1979) A natural compression law for soils (an advance on $e-\log p^{\prime}$ ). Géotechnique 29(4): 469-480, https://doi.org/10.1680/geot. 1979.29.4.469.

Campbell DJ (1975) Liquid limit determination of arable topsoils using a drop-cone penetrometer. Soil Science 26(3): 234-240, https://doi.org/ 10.1111/j.1365-2389.1975.tb01946.x.

Casagrande A (1932) Research on the Atterberg limits of soils. Public Roads 13(8): 121-136.

Casagrande A (1958) Notes on the design of the liquid limit device. Géotechnique 8(2): 84-91, https://doi.org/10.1680/geot.1958.8.2.84.

Das N, Sarma B, Singh S and Sutradhar BB (2013) Comparison in undrained shear strength between low and high liquid limit soils. International Journal of Engineering Research and Technology 2(1): $1-6$.

Dragoni W, Prosperini N and Vinti G (2008) Some observations on the procedures for the determination of the liquid limit: an application on Plio-Pleistocenic clayey soils from Umbria region (Italy). Italian
Journal of Engineering Geology and Environment 2008(Special Issue 1): 185-198, https://doi.org/10.4408/IJEGE.2008-01.S-12. Haigh SK (2012) Mechanics of the Casagrande liquid limit test. Canadian Geotechnical Journal 49(9): 1015-1023, https://doi.org/10.1139/ t2012-066.

Haigh SK (2016) Consistency of the Casagrande liquid limit test. Geotechnical Testing Journal 39(1): 13-19, https://doi.org/10.1520/ GTJ20150093.

Haigh SK, Vardanega PJ and Bolton MD (2013) The plastic limit of clays. Géotechnique 63(6): 435-440, https://doi.org/10.1680/geot.11.P.123.

ISI (Indian Standards Institution) (1985) IS2720-5: Determination of liquid limit by Casagrande apparatus. Bureau of Indian Standards, New Delhi, India.

Karlsson R (1961) Suggested improvements in the liquid limit test, with reference to flow properties of remoulded clays. In Proceedings of the Fifth International Conference of Soil Mechanics and Foundation Engineering. Dunod, Paris, France, vol. 1, pp. 171-184.

Kayabali K and Tufenkci OO (2010) Shear strength of remolded soils at consistency limits. Canadian Geotechnical Journal 47(3): 259-266, https://doi.org/10.1139/T09-095.

Ladd CC and Foott R (1974) New design procedure for stability of soft clays. Journal of the Geotechnical Engineering Division 100(7): $763-786$.

Leroueil S and Le Bihan JP (1996) Liquid limits and fall cones. Canadian Geotechnical Journal 33(5): 793-798, https://doi.org/10.1139/t96-104324.

Mitchell JK (2005) Fundamentals of Soil Behavior. Wiley, New York, NY, USA.

Nagaraj HB, Sridharan A and Mallikarjuna HM (2012) Re-examination of undrained strength at Atterberg limits water contents. Geotechnical and Geological Engineering 30(4): 727-736, https://doi.org/10.1007/ s10706-011-9489-7.

Nagaraj HB, Sravan MV and Deepa BS (2018) Factors influencing undrained strength of fine-grained soils at high water contents. Geomechanics and Geoengineering 13(4): 276-287, https://doi.org/10. 1080/17486025.2018.1445873.

Narain J and Ramanathan TS (1970) Variation of Atterberg limits in relation to strength properties of a highly plastic clay. Journal of Indian National Society of Soil Mechanics and Foundation Engineering 9(2): 117-128.

Norman LEJ (1958) A comparison of values of liquid limit determined with apparatus having bases of different hardness. Géotechnique 8(2): 79-83, https://doi.org/10.1680/geot.1958.8.2.79.

O'Kelly BC (2013a) Atterberg limits and remolded shear strength-water content relationships. Geotechnical Testing Journal 36(6): 939-947, https://doi.org/10.1520/GTJ20130012.

O'Kelly BC (2013b) Discussion of 'Enhancement of the shear strength of wastewater residuals using industrial waste by-products' by C Kayser, $\mathrm{T}$ Larkin and N Singhal. Journal of Environmental Engineering 139(2): 312-315, https://doi.org/10.1061/(ASCE)EE.1943-7870. 0000608 .

O'Kelly BC (2013c) Undrained shear strength-water content relationship for sewage sludge. Proceedings of the Institution of Civil Engineers Geotechnical Engineering 166(6): 576-588, https://doi.org/10.1680/ geng.11.00016.

O'Kelly BC (2014a) Characterisation and undrained strength of amorphous clay. Proceedings of the Institution of Civil Engineers - Geotechnical Engineering 167(3): 311-320, https://doi.org/10.1680/geng.11.00025.

O'Kelly BC (2014b) Drying temperature and water content-strength correlations. Environmental Geotechnics 1(2): 81-95, https://doi.org/ 10.1680/envgeo.13.00016.

O'Kelly BC (2014c) Closure to discussion by K. Prakash and A. Sridharan of 'Atterberg limits and remolded shear strength - water content relationships' [Geotechnical Testing Journal, Vol. 36, No. 6, 
Fallacy of wide undrained strength range at the Casagrande liquid limit O'Kelly pp. 939-947]. Geotechnical Testing Journal 37(4): 729-731, https:// doi.org/10.1520/GTJ20140041.

O'Kelly BC and Sivakumar V (2014) Water content determinations for peat and other organic soils using the oven-drying method. Drying Technology 32(6): 631-643, https://doi.org/10.1080/07373937.2013. 849728.

O'Kelly BC, Vardanega PJ and Haigh SK (2018) Use of fall cones to determine Atterberg limits: a review. Géotechnique 68(10): 843-856, https://doi.org/10.1680/jgeot.17.R.039.

Russel ER and Mickle JL (1970) Liquid limit values by soil moisture tension. Journal of the Soil Mechanics and Foundations Division 96(3): 967-989

Seed HB, Woodward RJ and Lundgren R (1964) Fundamental aspects of the Atterberg limits. Journal of the Soil Mechanics and Foundations Division 90(6): 75-106.

Sharma B and Bora PK (2003) Plastic limit, liquid limit and undrained shear strength of soil - reappraisal. Geotechnical and Geoenvironmental Engineering 129(8): 774-777, https://doi.org/10.1061/(ASCE)10900241(2003)129:8(774).

Sherwood PT (1970) The Reproducibility of the Results of Soil Classification and Compaction Tests. Department of Transport, London, UK, Transport and Road Research Laboratories, Report LR 339.

Sherwood PT and Ryley MD (1970) An investigation of a conepenetrometer method for the determination of the liquid limit. Géotechnique 20(2): 203-208, https://doi.org/10.1680/geot.1970.20.2. 203.

Skempton AW and Northey RD (1952) The sensitivity of clays. Géotechnique 3(1): 30-53, https://doi.org/10.1680/geot.1952.3.1.30.

Škopek J and Ter-Stepanian G (1975) Comparison of liquid limit values determined according to Casagrande and Vasilev. Géotechnique 25(1): 135-136, https://doi.org/10.1680/geot.1975.25.1.135.
Sridharan A and Prakash K (1998) Characteristic water content of a finegrained soil-water system. Géotechnique 48(3): 337-346, https://doi. org/10.1680/geot.1998.48.3.337.

Sridharan A and Prakash K (2000) Percussion and cone methods of determining the liquid limit of soils: controlling mechanisms. Geotechnical Testing Journal 23(2): 236-244, https://doi.org/10.1520/ GTJ11048J.

Terzaghi K (1926a) Principles of final soil classification. Public Roads 8(3): 41-53.

Terzaghi K (1926b) Simplified soil tests for subgrades and their physical significance. Public Roads 7(8): 153-170.

Vinod P, Deepa KA and Sridharan A (2013a) Remoulded shear strength at plastic and semi-solid states. Proceedings of the Institution of Civil Engineers - Geotechnical Engineering 166(4): 415-424, https://doi. org/10.1680/geng.11.00071.

Vinod P, Deepa KA, Sridharan A, Haigh S and Vardanega PJ (2013b) Discussion: Remoulded shear strength at plastic and semi-solid states. Proceedings of the Institution of Civil Engineers - Geotechnical Engineering 166(5): 515-517, https://doi.org/10.1680/geng.12.00093.

Wasti Y and Bezirci MH (1986) Determination of the consistency limits of soils by the fall-cone test. Canadian Geotechnical Journal 23(2): 241-246, https://doi.org/10.1139/t86-033.

Whyte IL (1982) Soil plasticity and strength - a new approach using extrusion. Ground Engineering 15(1): 16-24.

Wroth CP and Wood DM (1978) The correlation of index properties with some basic engineering properties of soils. Canadian Geotechnical Journal 15(2): 137-145, https://doi.org/10.1139/t78-014.

Youssef MS, El Ramli AH and El Demery M (1965) Relationships between shear strength, consolidation, liquid limit and plastic limit for remolded clays. In Proceedings of the Sixth International Conference on Soil Mechanics and Foundation Engineering. University of Toronto Press, Toronto, ON, Canada, vol. 1, pp. 126-129.

\section{How can you contribute?}

To discuss this paper, please submit up to 500 words to the editor at journals@ice.org.uk. Your contribution will be forwarded to the author(s) for a reply and, if considered appropriate by the editorial board, it will be published as a discussion in a future issue of the journal. 